\title{
Leadership in business communication
}

\author{
Svetlana Alekseevna Dubinko ${ }^{1 *}$, Irina Iosifovna $\mathrm{Klimova}^{2}$, Lizaveta Alegauna \\ Dubinka-Hushcha $^{3}$, and Galina Vladimirovna Klimova ${ }^{2} \dagger$ \\ ${ }^{1}$ Belarusian State University, Faculty of International Relations, Minsk, Belarus \\ ${ }^{2}$ Financial University under the Government of the Russian Federation, Faculty of International \\ Economic Relations, Moscow, Russia \\ ${ }^{3}$ Copenhagen Business School, Department of International Economics, Government and Business, \\ Copenhagen, Denmark
}

\begin{abstract}
In a geographically structured organization, where divisions are represented by geography or country, understanding cultural complexities is critical to business success. Cultural traditions can vary within individual groups and communities, not to mention the diversity of cultural traditions across countries and continents. These cultural differences are also represented in the concept of leadership, the latter being crucial for effective business communication and doing business both globally and locally. Such deep components of culture as values, beliefs, cognitive styles, relationship with the environment, attitude to social structure, time, communication change very slowly or do not change at all, even in our global world. They are also crucial for understanding leadership and behavioral norms in successful business communication under the conditions of digital economy. The study draws on a survey conducted among students, master students and alumni in Denmark and Belarus. The purpose of the study is to show that the global leadership style implies the variants which are sensitive to the national leadership styles to the extent that is most appropriate for the corporate climate and business interests.

Keywords: global leadership style, local leadership style, corporate governance, cultural values
\end{abstract}

\section{Introduction}

New challenges the world in general and the world of business in particular face change the notion of leadership, determine the interaction of the national and international, the role of women in management and their increasing number in management positions. The hypothesis of the present article is based on the assumption that the global leadership style is a kind of invariant style which comprises the best practices of multinationals and conglomerates which flexibly respond to the national styles and business environment. The purpose of the study is to show that the global leadership style implies the variants which are sensitive to the national leadership patterns to the extent that is most appropriate for the

\footnotetext{
*Corresponding author: svetlanadubinko@gmail.com

$\dagger$ Died July 25, 2021.
} 
corporate climate and business interests. The impact of cultural values on local leadership patterns is the subject of the present study. The choice of variants of global leadership under conditions of global economy is the object of the research. The theoretical concept of the research study is based on the analysis of the scientific literature on leadership of networking and task-orientation modes, management styles, cultural roots of leadership which is reflected in the research conducted by Auer-Rizz and Berry [1], Hofstede [2], Strang [3], Young [4]. The study of the impact of globalization and digital economy in the international trade on leadership styles and corporate culture could shed the light on the interaction between the global and local in management and the role of emotional, cultural, social, and collective intelligences beyond (IQ) in their practical implementation as underlined by many scientists Higgins [5], Livermore [6], Mchugh et al. [7].

\section{$1.1 \quad$ Literature Review}

\subsubsection{Leadership competences and cultural traditions in business communication}

Leadership competences in doing business are based on basic business strategies which imply decision making, team-building, branding, marketing and image, managing people, process and benefits, retaining customers, maintaining communication, personal decisions, actions, energy, and others as shown in the research conducted by Marsh [8], Leitch, Lancefield [9]. Cultural and cross-cultural competences require knowledge of one's own culture and cultural specifics of one's foreign business counterparts. Concepts of leadership, management and organization being culture-bound are based on cultural values and beliefs of different societies, which is shown by Lewis [10], Adler [11], Hills [12], Mulder [13], Klimova, Sharabarina, Tichova, Dubinka [14], Dubinko [15] in their studies on the subject. Maintaining communication as a business strategy has different patterns based on directness and indirectness, content and context. They actually show differences in prioritizing truth and clarity in business relationships based on the cultural concept of truth (candor, negotiating truth, etc.) developed by Lewis [10]. Multinational teams are becoming increasingly common with the globalization of cross-national business, so it becomes even more imperative that the composition of international teams, and particularly the choice of their leaders, be carefully considered.

\subsubsection{The global and local in leadership styles}

An efficient manager not only chooses proper strategy and other guidance patterns, but also, which is equally important, tries to be attuned to the signals that come back and be ready to respond, as follows from the study conducted by McNulty [16]. Creating a safe way for people to ask questions and share feedback is also important for fostering clarity to get the collective voice of the organization in a disciplined, coherent way as shown in the publications by Oshry [17], Bharti [18]. There is a natural tendency to defer to the highest-paid person's opinion (HPPO) - or highest ranked or degreed. However, the new tendency in international business banishes the "HPPO". It corresponds to the values-based leadership style which instills a common set of values in all employees, improving their cohesiveness and willingness to work. Values-based leaders, according to the concept worked out by Indeed Editorial Team [19], have specific traits and other qualities that make them the best at what they do. These new tendencies in developing leadership concept in the new digital era are expressed in the idea of collective intelligence which acts 
successfully in combination with emotional and cultural intelligences as follows from the works published by Peters [20], Dubinka-Hushcha [21].

Re-thinking globalization which meets the challenges of time in the new digital era has led us to take a more careful look at the nature of collective intelligence as one of the best remedies for self-destructive human activity. According to Levy in the interview taken by Peters [20], one of the fundamental aspects of globalization is the emergence of cyberculture, which propagates the co-presence and interaction of points anywhere in the physical, social and information space. Globalization produces new forms of localization in a dialectical relationship that Robertson [22] popularized as 'glocalisation', where globalization has involved the reconstruction of "home", "community" and "locality". The argument, commented on by Brenner [23], is indebted to Lefebvre's claim that "the worldwide does not abolish the local'. According to Urry [24], 'the global and local are inextricably and irreversibly bound together through a dynamic relationship'. The processes within corporate governance and managerial styles on the background of the new global changes lead us to the assumption that the global leadership style is a kind of invariant style which comprises the best practices of multinationals and conglomerates which flexibly respond to the national styles and business environment.

\section{Methods}

The experimental data were obtained and analyzed from the survey conducted with the participation of the representatives of two cultures: the Belarusian and the Danish. The choice was determined by the assumption that these two cultures are comparatively small with more feministic tendencies according to Hofstede's description of this dimension. However, these cultures have quite different indices on the scale of individualism and collectivism according to World Values Survey which is based on dimensionalizing cultures conducted by Hofstede (Hofstede, 2011). Thus, Denmark's index of individualism is 74, and that of Belarus - assumedly 39, similar to Russia and other Slavic countries. The data were gathered in November 2020 - April 2021 via a questionnaire in Mentimeter.com. The respondents were divided into 3 categories (students, master students, and alumni) from two universities: Copenhagen Business School (CBS) and the Belarusian State University (BSU), Department of English for Economics. Three groups of respondents were chosen for the research study to obtain more detailed information about the approaches to leadership in business and compile the data from the students of world economy, who have rather theoretical knowledge of leadership styles, master students, who combine theory with its practical implementation, and alumni, who have more than five years of experience working in multinational teams.

\section{$3 \quad$ Results}

The respondents were provided with a special code to answer the questionnaire electronically. Mentimeter.com aggregated the results into graphics automatically for each group; based on these results, tables comparing the same groups from both universities were designed in Excel. Based on these tables, pie charts and series were designed in order to visualize the results. The difference of 04-05 and higher in the answers given by the students, master students and alumni was taken into consideration. 

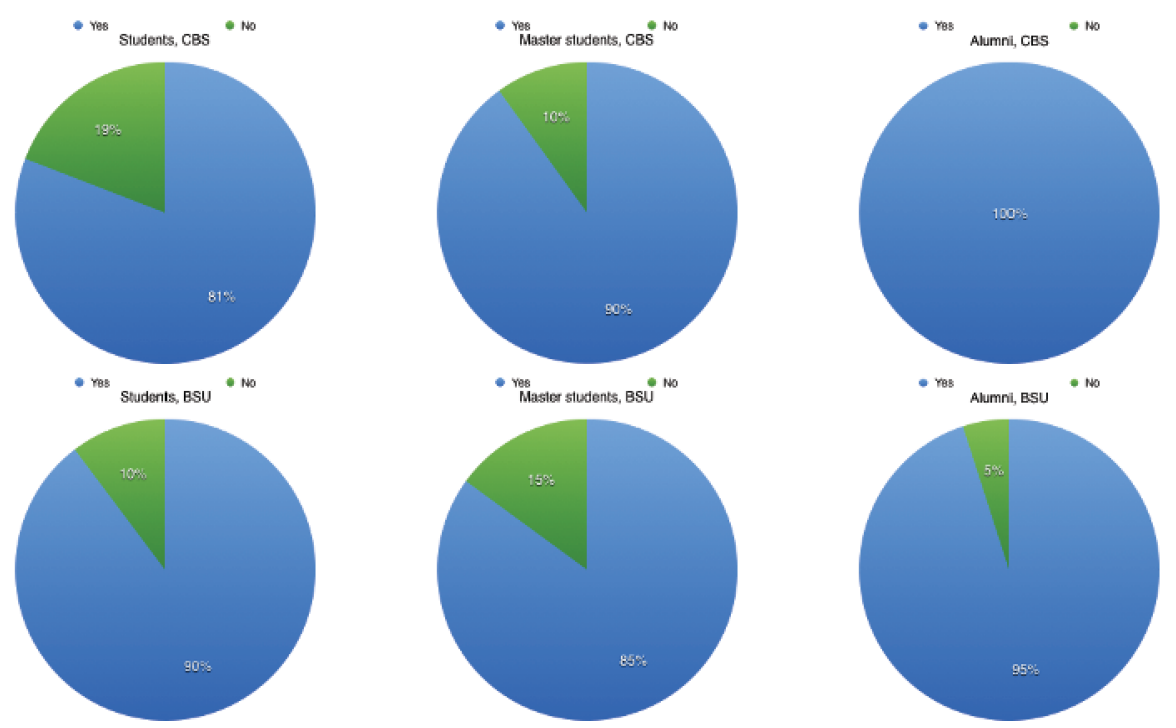

Fig. 1. Question "Will the role of an organizational leader be transformed in the digital economy?".
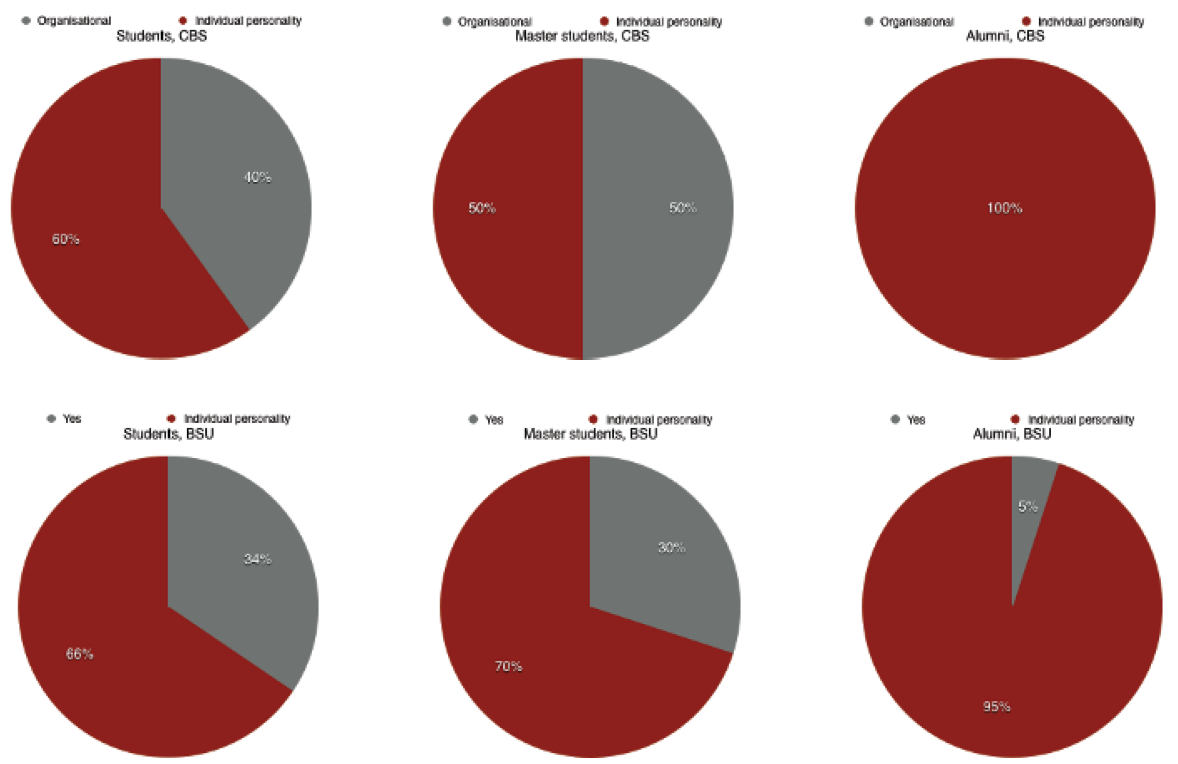

Fig. 2. Question "Is leadership an organizational or individual personality phenomenon?". 


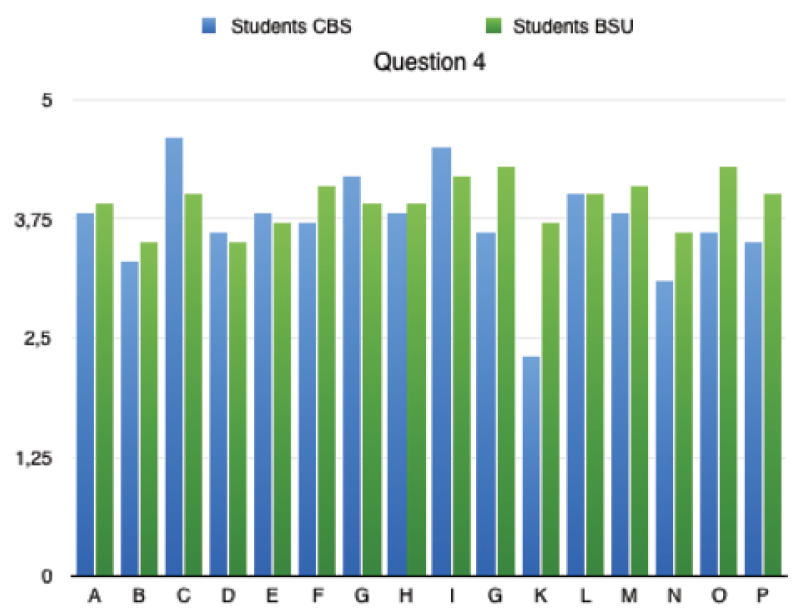

Master students CBS

a)

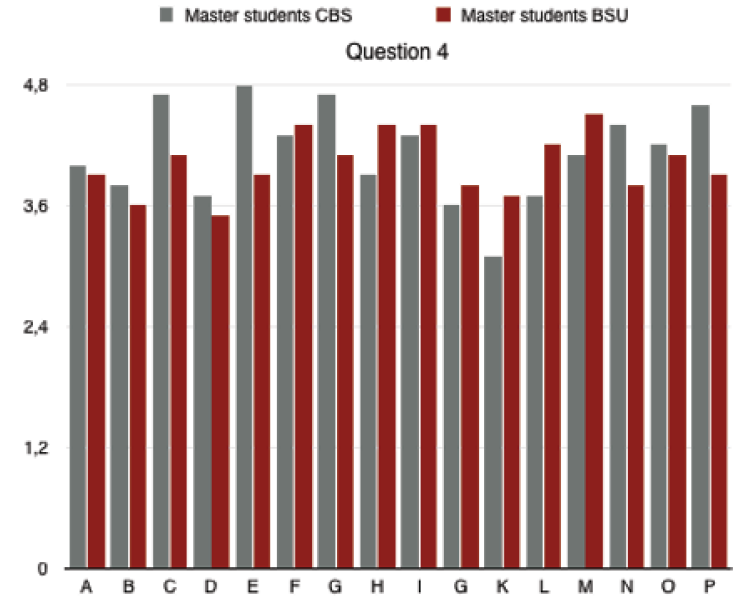

b)

Alumni CBS

Alumni BSU

Question 4

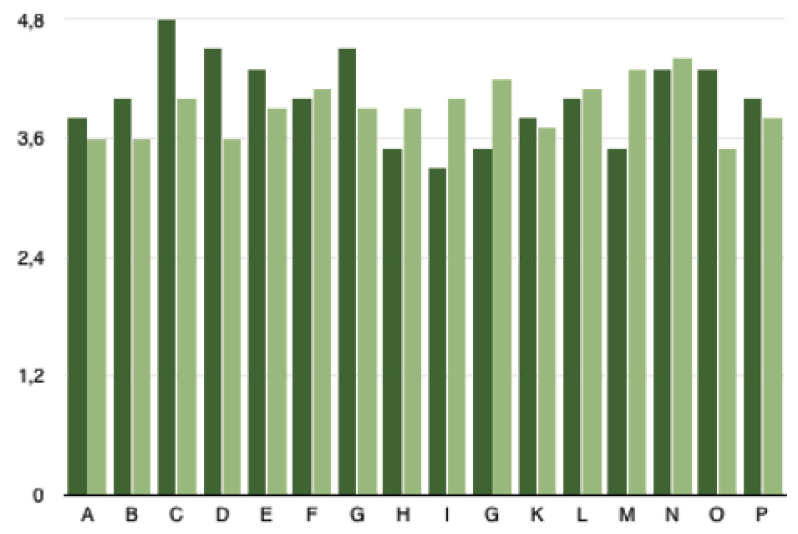

c)

Fig. 3. Question "What leadership competencies will become the most important in an organization in a digital economy? Rate on a 5-point scale". 
Table 1. Leadership in digital economy.

\begin{tabular}{|l|c|c|c|c|}
\hline $\begin{array}{c}\text { What is more } \\
\text { important for } \\
\text { organisational leaders } \\
\text { in the digital economy? }\end{array}$ & Leading oneself & Leading others & Leading a team & $\begin{array}{c}\text { All of the } \\
\text { above }\end{array}$ \\
\hline Students CBS & 0 & 5.5 & 27.8 & 66.7 \\
\hline Students BSU & 10.7 & 0 & 28.5 & 60.7 \\
\hline Master students CBS & 11.1 & 11.1 & 33.3 & 44.4 \\
\hline Master students BSU & 30 & 0 & 40 & 30 \\
\hline Alumni CBS & 0 & 0 & 25 & 75 \\
\hline Alumni BSU & 15 & 0 & 30 & 55 \\
\hline
\end{tabular}

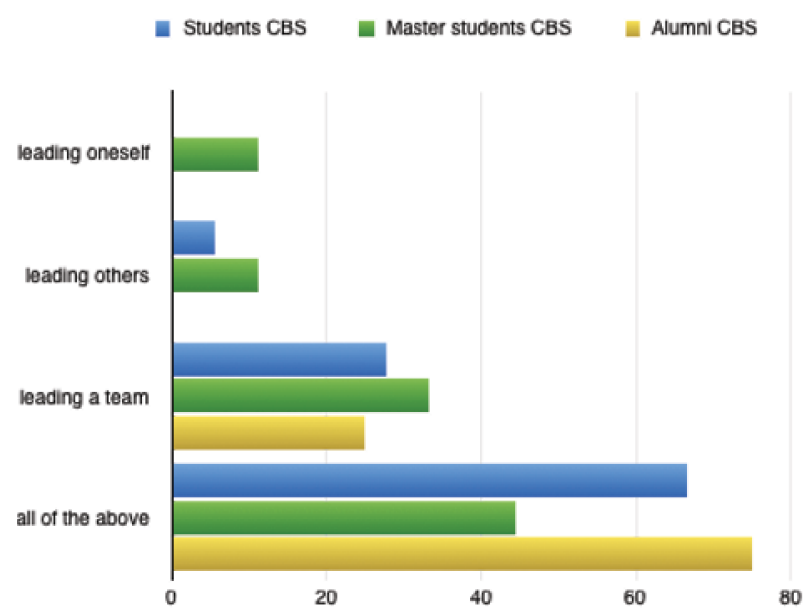

Fig. 4. Comparison of all three groups from CBS.

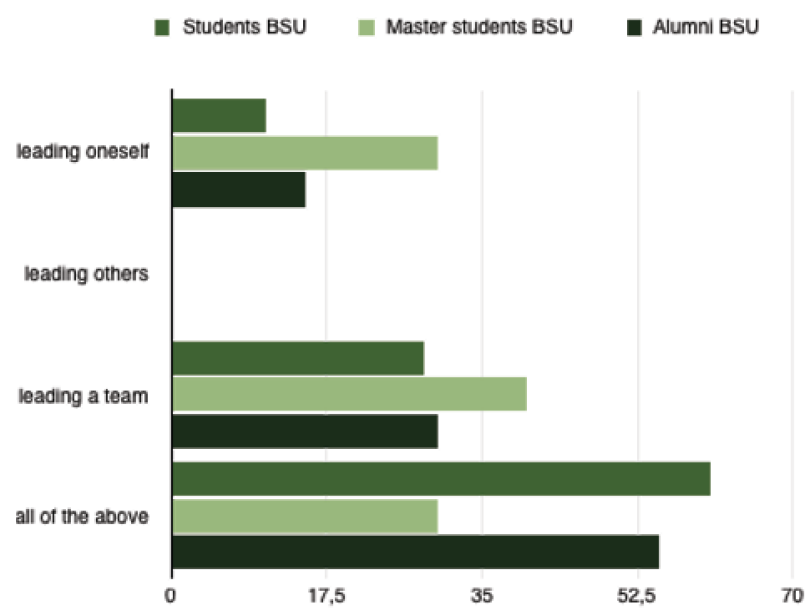

Fig. 5. Comparison of all three groups from BSU. 


\section{Discussion}

The proportion of positive answers to the question "Will the role of an organizational leader be transformed in the digital economy?" was increasing in the same pattern among the students, master students and alumni from CBS and BSU participants (Fig. 1).

The question in Fig. 2 "Is leadership an organizational or individual personality phenomenon?" was testing differences in the global and the local leadership styles. The results demonstrate the same tendency between the students from CBS and BSU in favor of the individual personality phenomenon. However, it is interesting to observe an equal distribution of answers between master students from BSU compared to more inclination towards individualistic style among master students from CBS. 100\% of alumni from Belarus believe that leadership is an individualistic personality phenomenon, whereas $5 \%$ of alumni from Denmark see leadership as an organizational experience (Fig. 2).

Question in Fig. 3, a, b, c "What leadership competencies will become the most important in an organization in a digital economy?" was rated on a 5-point scale. The following competences were rated:

A. Ability to ensure the integrity and unity of the organization.

B. Ability to captivate by personal example and to be responsible for their actions and decisions.

C. Ability to adapt to changes in business environment.

D. Ability to quickly shift a leadership role in various situations.

E. Organizational and communication skills.

F. Ability to formulate goals.

G. Ability to motivate employees.

H. Ability to organize a system for collecting the necessary information.

I. Ability to think conceptually, combining the goals of all departments in decision-making, to see the connection between the whole and a part.

J. Ability to predict various development scenarios.

$\mathrm{K}$. Being a tenacious business person.

L. Ability to create a network of cross-functional teams.

M. Ability to work in a cross-functional team.

N. Ability to ensure staff development.

O. Ability to achieve high performance.

P. Ability to delegate authority to subordinates.

The difference of 0.4-0.7 in the answers given by the students-respondents was observed between the students of CBS and BSU in the positions $\mathrm{C}, \mathrm{F}, \mathrm{I}, \mathrm{J}, \mathrm{K}, \mathrm{N}, \mathrm{O}, \mathrm{P}$ with CBS students leading in the positions C, I (Fig. 3, a, b, c).

The BSU master students were leading in the positions H, K, L, M and the CBS master students - in the positions C, G, N, P.

The alumni category has shown the difference between the BSU and CBS students in the positions B, C, D, E, G, H, I, J, M, O. The BSU was leading in the positions H, I, J, M. CBS was marked in the positions B, C, D, E, G, O.

The answers to Question in Table 1 "What is more important for organizational leaders in the digital economy?" show the tendency observed between the students and the alumni of the BSU and CBS to prioritize the position "all the above" (Table 1, Figures 4, 5), thus underlining the importance of all the positions combined for organizational leaders in the digital economy. 


\section{Conclusion}

The results of the study have shown some unanimous opinions and the similarities between all the three BSU and CBS groups which are observed in the positions: the ability to ensure the integrity and unity of the organization and the ability to create a network of cross-functional teams and may be regarded as universal strategies. The data obtained as a result of the survey show that the majority of the respondents of the three groups both from the BSU and CBS believe that the role of an organizational leader will be transformed in the digital economy, which is a good reason to assume that the global leadership style is a kind of invariant style which comprises the best practices of multinationals and conglomerates which flexibly respond to the national styles and business environment. Most of the respondents from all the BSU groups (more than 50\%) consider that leadership is an individual personality phenomenon with the same tendency in CBS groups. This tendency is more vividly observed in the alumni BSU group (100\%). 5\% of the alumni from Denmark see leadership as an organizational experience. It means that the presumably collectivistic pattern of the Belarusian culture and individualistic pattern of the Danish culture is not entirely confirmed as far as leadership styles in international business are concerned. It is evident that the culture patterns under the research study combine the features of different cultural dimensions to the extent which is due to the interaction of global and local factors. It underlines a strong influence of global leadership style on the local leadership patterns, which proves our initial assumption and hypothesis. The difference in the priority of leadership strategies in business communication in multinational teams in the era of globalization presupposes the study and effective use of collective intelligence in combination with emotional and cultural intelligences, which should be the priority of the leadership strategy of international conglomerates.

\section{References}

1. A.-R. Werner, M. Berry, J Bus Comm, 37(3) (2000). https://doi.org/10.1177/002194360003700304

2. G. Hofstede, Online Read Psyc Cult, 2, 8 (2011). http://dx.doi.org/10.9707/2307-0919.1014

3. K.D. Strang, Collaborative Synergy and Leadership in E-Business, in Handbook of Research on Electronic Collaboration and Organizational Synergy (Central Queensland University, 2009). https://doi.org/10.4018/978-1-60566-106-3.ch028

4. Y.Y. Kim, The International Encyclopedia of Intercultural Communication (Wiley-Blackwell, 2017). https://doi.org/10.1002/9781118783665

5. I. Alon, J.M. Higgins. Bus Horizons, 48(6), 501-512 (2005). https://doi.org/10.1016/j.bushor.2005.04.003

6. D. Livermore, Leading with cultural intelligence: The real secret to success (AMACOM, 2015)

7. K. Mchugh, et al., Leadership Quart, 27(2), 218-241 (2016). https://doi.org/10.1016/j.leaqua.2016.01.001

8. RA Marsh, Top 10 Best Strategies for Business Success. Experts discuss essentials of running a business (2021). Accessed on: October 13, 2021. [Online]. Available: 
https://inbusinessphx.com/building-your-business/top-10-best-strategies-business-succ ess\#.YToRN27RbGI

9. J. Leitch, D.M. Lancefield, How to develop and retain leaders who can guide your organization through times of fundamental change, in D. Cross (ed), Ten Principles Collection, 33-53 (PwC, 2020)

10. R.D. Lewis, When Cultures Collide: Leading Across Cultures (Nicholas Brealey International, 2006)

11. N.J. Adler, Int Execut, 28(1), 31-32 (1986). https://doi.org/10.1002/tie.5060280112

12. M. Hills, Online Read Psyc Cult, 4(4) (2002). https://doi.org/10.9707/2307-0919.1040

13. P. Mulder, Trompenaars Cultural Dimensions. Accessed on: October 13, 2021. [Online]. Available:

https://www.toolshero.com/communication-skills/trompenaars-cultural-dimensions/

14. I.I. Klimova, et al., Communicative Competence Enhancement. XLinguae, 1XL, 67-74 (2018). https://doi.org/10.18355/XL.2018.11.01XL.07

15. S. A. Dubinko, Intercultural competence in effective business communication, in Teaching Foreign Languages in Polycultural World: Traditions, Innovations, Perspectives: materials of the 3-d International scientific and practical conference, 14-18, Minsk, March, 25, 2021, Belarusian State Pedagogical University named after M. Tank (BSPU, Minsk, 2021)

16. E.J. McNulty, Can you handle the truth? (2021). Accessed on: October 13, 2021. [Online]. Available: https://www.strategy-business.com/blog/Can-you-handle-the-truth

17. B. Oshry, Total system power developers, fixers, integrators, and validators (2020). Accessed on: October 13, 2021. [Online]. Available: https://govleaders.org/total-system-power.htm

18. N.L. Bharti, Administrative thinker (2020). Accessed on: October 13, 2021. [Online]. Available:https://www.lkouniv.ac.in/site/writereaddata/siteContent/2020040709482632 55nlbharti_Douglas_McGregor.pdf

19. Values-Based Leadership: Traits and Benefits. Indeed Editorial Team. Accessed on: October 13, 2021. [Online]. Available: https://www.indeed.com/career-advice/career-development/values-based-leadership

20. M.F. Peters, Interview with Pierre A. Levy, French philosopher of collective intelligence (2015). Accessed on: October 13, 2021. [Online]. Available: https://doi.org/10.1080/23265507.2015.1084477

21. L.A. Dubinka-Hushcha, Augmenting collective intelligence through blended learning and open educational resources, in Intercultural Communication and Professionally Oriented Teaching Foreign Languages: materials of the 13th international scientific conf., 105-109, Minsk, October 30, 2019, Belarusian State University (BSU, Minsk, 2019)

22. R. Robertson, Glocalization: Time-Space and Homogeneity-Heterogeneity, in M. Featherstone, S. Lash, R. Robertson (eds), Global Modernities, 25-44 (Sage Publications, London, 1995). http://dx.doi.org/10.4135/9781446250563.n2

23. N. Brenner, Int J Urban Reg Res, 24(2), 361-378 (2003). https://doi.org/10.1111/1468-2427.0023

24. J. Urry, Sociology Beyond Societies: Mobilities for the Twenty-First Century (Routledge, London, 1999). https://doi.org/10.4324/9780203021613 